\title{
Relação médico-paciente: a essência perdida
}

\author{
Physician-patient relationship: the lost essence \\ Relación médico-paciente: la esencia perdida
}

João Macêdo Coelho Filho'

Os avanços da medicina não estão reconhecidamente associados à maior satisfação dos médicos com a profissão (Smith, 2001). Por sua vez, os pacientes encontram-se descontentes no que se refere à relação com os médicos. Esses fatores, somados à preocupação com o aumento dos custos com a assistência e a eclosão de questões conflituosas entre usuários e prestadores de serviços na área de saúde, conferem um interesse renovado a estudos e reflexões sobre a relação médico-paciente (RMP). Daí, a relevância do artigo de Ruiz-Moral, tratando a RMP particularmente com vistas à educação médica. RMP engendra questões que dizem respeito à natureza da própria medicina, que, nos tempos atuais, adquire contornos ainda mais complexos. Citem-se: a complexidade tecnológica incorporada ao trabalho do médico; o estreitamento entre a prática da medicina e as leis de mercado; a consciência crescente acerca dos direitos dos pacientes, entre outros.

Para analisar a RMP com vistas a seu ensino em nível de graduação e pósgraduação, parece-nos interessante focalizá-la com base nas etapas que caracterizam o percurso do profissional médico desde o momento da escolha da profissão, palmilhando a graduação, até o contexto de sua prática profissional. Iniciemos pela decisão do jovem estudante em cursar medicina. Quais os aspectos subjetivos envolvidos nessa escolha? O discurso dos próprios estudantes, quando já iniciados no curso médico, dá conta de razões como o desejo de ajudar os outros; de trabalhar com demandas humanas; de salvar vidas; e de acolher e mitigar o sofrimento das pessoas (Grosseman \& Patrício, 2002). Outras motivações, inconscientes ou não, poderiam ser contempladas, como: o desejo de sucesso profissional e financeiro; o reconhecimento social e o fascínio de ter o domínio e ascendência sobre o outro. Independente de razões específicas, o que se percebe é uma tendência à dissolução de quase todas elas ao longo da trajetória do curso médico até a prática profissional. ${ }^{1}$ Médico; doutor em Farmacologia; professor de Geriatria, Faculdade de Medicina, Universidade Federal do Ceará. Fortaleza, CE.
$<$ <macedocoelho@yahoo.com.br>

Rua Eduardo Garcia, 650, apto. 1400

60.150-100 


\section{DEBATES}

O contato com o humano e todas as suas dimensões, objeto de desejo daquele jovem, na formação médica vai sendo sufocado por uma prática com ênfase na doença. O diálogo com os pacientes é pautado predominantemente pela exploração dos sinais, sintomas e manifestações laboratoriais dos agravos. Uma prática repetitiva, sem dar conta das singularidades inerentes ao encontro médico-paciente. Alcançada a prática profissional, grande parte dos médicos defrontar-se-á com condição desfavorável de trabalho, estando nem sempre configurado o sucesso financeiro, pelo menos nos moldes planejados (o que seria concebido como sucesso financeiro é algo variável conforme as profissões e determinado pelos valores da sociedade).

As consultas médicas desenvolvem-se em tempo exíguo, mesmo em atenção primária, sendo favorecedoras de encontro superficial entre o profissional de saúde e os seus pacientes (Caprara \& Rodrigues, 2004). O conjunto de frustrações de expectativas, desejos e sonhos acaba por conformar um profissional cético quanto à possibilidade (e necessidade) de uma prática médica humanizada. Um profissional que vai se permitindo, pelas condições impostas, a desenfatizar, cada vez mais, os pressupostos de uma RMP centrada no paciente e sua experiência da doença e do sofrimento. O que resta ao homem depois que seus sonhos (ou parte deles) vão embora? O que fazer de verdadeiramente humano quando os sonhos são dissolutos?

Enfatizar o ensino da RMP passa, por conseguinte, a ser uma estratégia valiosa para a superação desse desencontro da medicina com sua essência. Dada a complexidade imbricada no tema, deve se configurar não somente na introdução de conteúdos longitudinais no curso médico, mas de um movimento que se contrapõe ao modelo prevalente de prática médica, daí suas limitações e desafios, mas também sua necessidade. Muitos médicos dariam o melhor de si na consulta se tivessem sido efetivamente treinados quanto a aspectos da RMP. O problema é justamente o "efetivamente treinados". Muito tem se falado sobre RMP e sua inserção como tópico fundamental do ensino médico. A exploração da experiência do paciente, interpretando os significados socioculturais de suas queixas, respeitando seus valores, e o estabelecimento, em comum, de um plano de tratamento têm sido amplamente defendidos. Igualmente, a necessidade de se abordar e explorar a dimensão simbólica e psíquica do adoecer. Parece-nos que o que ainda é pouco destacado é o enfoque do "como fazê-lo". Aqui reside o problema dos conteúdos e, fundamentalmente, dos métodos de ensino-aprendizagem. Sem recursos interativos e práticos, incorporando a tecnologia existente relacionada ao encontro médicopaciente, o ensino da RMP passa a ser retórico. Da mesma forma, se não ocorrer a mudança de prática dos próprios docentes, que são o espelho na formação dos alunos.

Nesse contexto, o enfoque das habilidades de comunicação apresenta-se como fundamental. Deve começar com questões básicas, como o procedimento de obtenção de informações do paciente (tipos de perguntas; formulações das mesmas; interpretação de discurso, entre outros), e progredir até tópicos relacionados à negociação do plano de tratamento. Esse enfoque, em muito, poderia contribuir para a realidade preocupante em que 54\% dos distúrbios percebidos pelos pacientes não são levados em consideração pelos médicos durante as consultas (Stewart et al., 1979). A introdução de conteúdos relacionados às chamadas humanidades médicas também é crucial na formação do médico, quer seja como um meio (por exemplo, o uso da literatura e cinema em aulas) ou um fim (sensibilidade artística é condição indispensável ao médico).

A apresentação da RMP como uma técnica, conforme assinalado por Ruiz-Moral, é interessante no sentido de definir seu lugar na formação do médico e a necessidade de uma teoria e prática subjacentes. Porém, cautela é requerida quanto à possibilidade de ser entendida como procedimento de competência de clínicos, em particular, os generalistas. $\mathrm{Na}$ medicina científica, geralmente, os procedimentos são vinculados a determinadas especialidades.

Por último, uma questão importante: todos os estudantes e médicos responderiam igualmente às intervenções de ensino relativo à RMP? Provavelmente não, dado que nem todos 
- é preciso reconhecer -, são possuidores dos atributos de personalidade e vocação indispensáveis à condição de ser médico. Nesse sentido, a seleção para ingresso no curso médico deveria necessariamente considerar esses atributos, a exemplo do que é feito em outras áreas. Em resumo, o artigo de Ruiz Moral tem a importância de deflagrar reflexões teóricas importantes sobre a RMP, posicionando-a como elemento central da formação do médico.

\section{Referências}

CAPRARA, A.; RODRIGUES, J. A relação médico-paciente: repensando o vínculo terapêutico. Ciênc. Saúde Colet., v.9, n.1, p. 139-46, 2004.

GROSSEMAN, S.; PATRÍCIO, Z.M. A relação médico-paciente e o cuidado humano: subsídios para promoção da educação médica. Rev. Bras. Educ. Med., v.28, n.2, p.99-105, 2004.

SMITH, R. Why are doctors so unhappy. BMJ, n.322, p.1073-4, 2001.

STEWART, M.A.; MCWHINNEY, I.R.; BUCK, C.W. The doctor-patient relationship and its effect upon outcome. J. R. Coll. Gen. Pract., n.29, p.77-82, 1979. 